\title{
Adaptive Rat Swarm Optimization for Optimum Tuning of SVC and PSS in a Power System
}

\author{
Ali Toolabi Moghadam (D), ${ }^{1}$ Morteza Aghahadi $\left(\mathbb{D},{ }^{1}\right.$ Mahdiyeh Eslami $\mathbb{D},{ }^{2}$ Shima Rashidi $\left(\mathbb{D},{ }^{3}\right.$ \\ Behdad Arandian ${ }^{(D},{ }^{4}$ and Srete Nikolovski ${ }^{5}{ }^{5}$ \\ ${ }^{1}$ School of Industrial and Information Engineering, Polytechnic University of Milan, Milan, Italy \\ ${ }^{2}$ Department of Electrical Engineering, Islamic Azad University, Kerman Branch, Kerman, Iran \\ ${ }^{3}$ Department of Computer Science, College of Science and Technology, University of Human Development, Kurdistan Region, \\ Sulaymaniyah, Iraq \\ ${ }^{4}$ Department of Electrical Engineering, Islamic Azad University, Dolatabad Branch, Isfahan, Iran \\ ${ }^{5}$ Power Engineering Department, Faculty of Electrical Engineering, Computer Science and Information Technology, \\ University of Osijek, Osijek 31000, Croatia
}

Correspondence should be addressed to Mahdiyeh Eslami; mahdiyeh_eslami@yahoo.com

Received 16 October 2021; Revised 24 November 2021; Accepted 3 December 2021; Published 31 January 2022

Academic Editor: Pawan Sharma

Copyright ( 92022 Ali Toolabi Moghadam et al. This is an open access article distributed under the Creative Commons Attribution License, which permits unrestricted use, distribution, and reproduction in any medium, provided the original work is properly cited.

\begin{abstract}
This paper presents a new approach for the coordinated design of a power system stabilizer- (PSS-) and static VAR compensator(SVC-) based stabilizer. For this purpose, the design problem is considered as an optimization problem, while the decision variables are the controllers' parameters. This paper proposes an effective optimization algorithm based on a rat swarm optimizer, namely, adaptive rat swarm optimization (ARSO), for solving complex optimization problems as well as coordinated design of controllers. In the proposed ARSO, instead of a random initial population, the algorithm starts the search process with fitter solutions using the concept of the opposite number. In addition, in each iteration of the optimization, the new algorithm replaces the worst solution with its opposite or a random part of the best solution to avoid getting trapped in local optima and increase the global search ability of the algorithm. The performance of the new ARSO is investigated using a set of benchmark test functions, and the results are compared with those of the standard RSO and some other methods from the literature. In addition, a case study from the literature is considered to evaluate the efficiency of the proposed ARSO for coordinated design of controllers in a power system. PSSs and additional SVC controllers are being considered to demonstrate the feasibility of the new technique. The numerical investigations show that the new approach may provide better optimal damping and outperform previous methods.
\end{abstract}

\section{Introduction}

The stability of power systems has become an important area of study, and this is mostly due to the integration of power systems. As a result, more advanced control equipment and stronger protection schemes have been added to the power system to increase stability. The electromechanical oscillations, which can be classified into interarea and local modes, are observed in the power system following the unbalance between mechanical and electrical torques at the synchronous generator, caused by the variation of power system topology or loads [1]. When these low-frequency oscillations (LFOs) are poorly damped, the generator rotor shaft and the power transfers are highly affected. The reliability and security of a power system are highly affected by these oscillations [2].

To face these adverse phenomena, power system stabilizers (PSSs) have long been used to improve power system stability and enhance system damping of oscillation modes. These stabilizers are employed to add damping torque to the generator rotor oscillations derived from speed, frequency, or power of the generator where it is connected $[3,4]$. 
Unfortunately, some weakness is encountered in the damping of interarea oscillations, and other solutions need to be involved. In recent years, power electronic-based flexible AC transmission system (FACTS) controllers, which are based on power electronics, have been considered as efficient alternative solutions [5]. Generally, FACTS devices have been employed for handling different power system control problems $[6,7]$. In other words, they can increase power transfer capability and improve power system stability and controllability. However, the combination of PSSs and FACTS devices in the same network has raised a new problem in terms of coordination between these regulators. Indeed, it is essential to ensure that there is a good coordination between these devices in a way that their actions are not negative in view of the security of the network.

One of the well-known shunt FACTS devices, named static VAR compensator (SVC), is considered a competent device to provide adequate damping of the LFOs in modern power systems after the apparition of disturbances [8]. It also has the capability of regulating bus voltage at its terminals by injecting controllable reactive power into the power network through the bus where it is connected. In the last few years, many research studies have proposed design techniques for SVC devices to enhance power system stability. Furthermore, other proprieties of the power system can be improved, such as dynamic control of power flow, steady-state stability limits, and damping of electromechanical oscillations [9]. Uncoordinated design between SVC and PSS causes the system to become unstable. Therefore, stability and damping modes are essential to optimal coordinated design between PSS- and SVC-based controllers. A comprehensive study of the PSS and SVC controllers when applied in a coordinated manner and also separately has been conducted in [10].

The problem of designing the power system controller's parameters is formulated as a nondifferentiable, large-scale nonlinear problem. This optimization problem is hard to solve by employing traditional optimization techniques such as sequential quadratic programming (SQP) techniques due to their high sensitivity to the initial point [11]. Furthermore, these methods require a long time in the convergence process. To overcome the drawbacks mentioned earlier, intelligent techniques are involved in real-life engineering problems, including power system stability [12-14]. Most of this research has been focused on the coordinated design of SVC and PSS controllers. For coordinated design of power system controllers, a large number of such algorithms have recently been offered, including Teaching-Learning Algorithm (TLA) [15], Bacterial Foraging Optimization (BFO) [16], Brainstorm Optimization Algorithm (BOA) [17], Coyote Optimization Algorithm (COA) [18], ant colony optimization (ACO) [19], bat algorithm (BAT) [20], bee colony algorithm (BCA) [11], Genetic Algorithm (GA) [21], particle swarm optimization (PSO) [22], flower pollination algorithm (FPA) [23], gravitational search algorithm (GSA) $[24,25]$, sine-cosine algorithm (SCA) [26], grey wolf optimizer (GWO) [27], firefly algorithm (FA) [28], Differential Evolution (DE) [29], Biogeography-Based Optimization
(BBO) [30], Cuckoo Search (CS) algorithm [31], Harmony Search (HS) [32], Seeker Optimization Algorithm (SOA) [33], Imperialist Competitive Algorithm (ICA) [34], Harris Hawk Optimization (HHO) [35], Sperm Swarm Optimization (SSO) [36], Tabu Search (TS) [37], Simulated Annealing [38], Multi-Verse Optimizer (MVO) [39], MothFlame Optimization (MFO) [40], and collective decision optimization (CDO) [41]. Although metaheuristic algorithms could provide relatively satisfactory results, no algorithm could provide superior performance than others in solving all optimizing problems. Therefore, several studies have been conducted to improve the performance and efficiency of the original metaheuristic algorithms in some ways and apply them for a specific purpose [42-51].

One of the most recent bioinspired population-created metaheuristic algorithms for complex optimization problems is the rat swarm optimizer (RSO) [52]. The RSO algorithm mimics the following and attacking performances of rats in nature. Like the other population-based techniques, RSO, without any information about the solution, utilizes random initialization to generate the candidate. Compared to the other metaheuristics, RSO possesses several advantages. It has a very simple structure and a fast convergence rate and can be easily understood and utilized.

However, like other metaheuristic algorithms, RSO commonly suffers from getting trapped in local minima when the objective function is complex and includes a rather large number of variables. This paper presents an effective modification to overcome the mentioned weaknesses in the algorithm. In the proposed ARSO, both the initial random solutions and their opposites are evaluated in the first iteration of the algorithm, and if the opposite solution's fitness is lower than the random one, the opposite solution will be selected. As a result, the algorithm begins with better solutions instead of random ones. Furthermore, the new algorithm replaces the worst solution with a better one at each iteration to improve the algorithm's exploration capabilities as well as its performance and convergence rate. To authenticate the robustness of the suggested ARSO, a set of benchmark functions from the literature are employed. The numerical findings reveal that the ARSO converges faster and significantly outperforms the RSO and some well-known optimization algorithms. In addition, the performance and efficiency of the new method are investigated through numerical experiments with the oscillation damping controller. The numerical analyses are applied on a case study system by designing a PSS and SVC controller. Simulation results confirm the advantage of the ARSO algorithm in design controllers.

The rest of this paper is organized as follows: Section 2 presents the optimization problem formulation and the model of a power system. Rat swarm optimization is explained in Section 3. Section 4 contains the presentation of the proposed optimization technique. Model verification is presented in Section 5. A discussion of simulation results is presented in Section 6. Finally, the study's conclusions and future work are summarized in Section 7. 


\section{Optimization Problem Formulation}

The general form of a constraint optimization problem can be expressed mathematically as follows:

$$
\begin{aligned}
& \operatorname{minimize} f(X) \\
& \text { subject to } g_{i}(X) \leq 0, i=1,2, \ldots, p \\
& h_{j}(X) \leq 0, j=1,2, \ldots, m \\
& X^{L} \leq X \leq X^{U}
\end{aligned}
$$

where $X$ is an $n$-dimensional vector of design variables, $f(X)$ is the fitness function which returns a scalar value to be minimized, and $g(X)$ and $h(X)$ are inequality and equality constraints, respectively. $X^{L}$ and $X^{U}$ are the boundary constraints. Many optimization methods have been developed over the last few decades. Metaheuristics are a new generation of optimization methods that are proposed to solve complex problems.

2.1. Power System Model. The standard modeling for power systems is based on a set of nonlinear differential algebraic calculations, which are as follows:

$$
\dot{X}=f(X \cdot U) \text {, }
$$

where $x=\left[\delta, \omega, E_{q}, E_{f d}\right]$ is the state variable vector and $u=$ $\left[u_{\mathrm{PSS}}, u_{\mathrm{svc}}\right]$ is the input control parameter vector. The linear equation with PSS and SVC controllers is obtained by the following equation:

$$
\dot{X}=A X+B U \text {. }
$$

At a certain operating point, both $A$ and $B$ are evaluated. The goal of the optimum design is to put the state matrix modes on the left side.

2.1.1. PSS Structure. The phase lag between the exciter input and machine electrical torque is compensated by PSS. An additional stabilizing signal is presented through the excitation system to achieve this goal. PSS generates the necessary torque on the machine's rotor. The additional stabilizing signal and the speed are proportional. As shown in Figure 1, this stabilizer style consists of a dynamic compensator and a washout filter. The washout filter, which is primarily a high-pass filter, will remove the mean component of PSS's output. In general, the constant value of time can be anywhere between 0.5 and 20 seconds.

2.1.2. SVC-Based Damping Controller Model. Figure 2 shows the SVC structure in this study, which is a fixed capacitor thyristor-controlled reactor. The firing angle varies between 90 and 180 degrees depending on the capacitor voltage [53].

Figure 3 shows an SVC-based damping controller that acts as a lead-lag compensator and consists of two stages of the lead-lag compensator, a signal-washout block, and a gain block. SVC has the following dynamic equation:

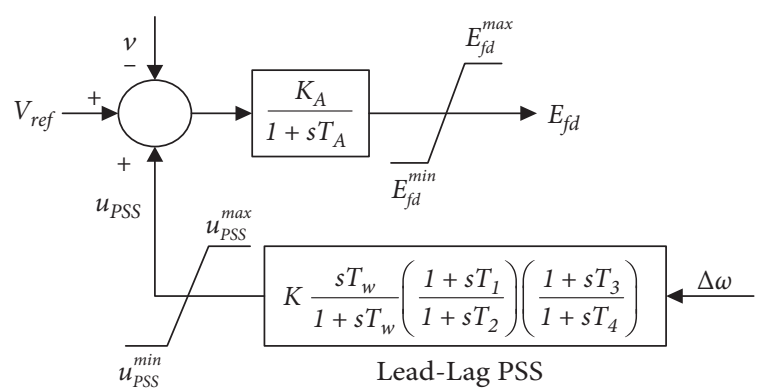

FIgURe 1: Lead/lag PSS.

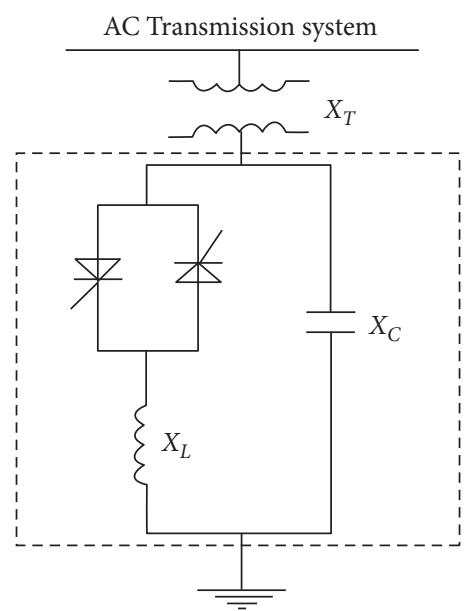

FIgURe 2: Modeling the SVC.

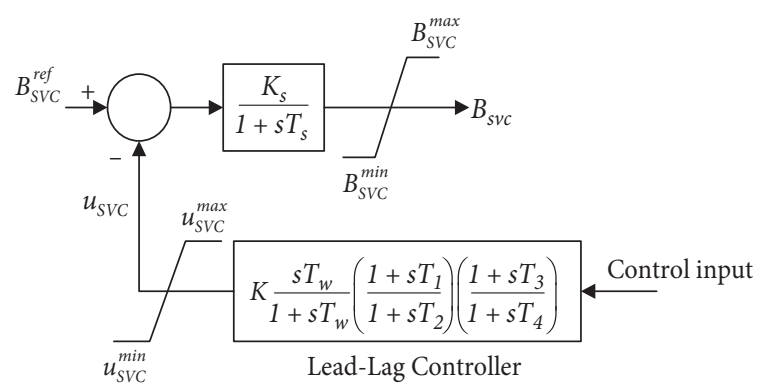

FIGURE 3: SVC with a lead-lag controller.

$$
\dot{B}_{\mathrm{SVC}}=\frac{\left(K_{s}\left(B_{\mathrm{SVC}}^{\mathrm{ref}}-u_{\mathrm{SVC}}\right)-B_{\mathrm{SVC}}\right)}{T_{s}} .
$$

2.2. Problem Formulation. In the suggested technique, the optimum parameters are obtained under various operating conditions and disturbances. First, an appropriate objective function should be presented for tuning design. In this research, ARSO is employed to better optimize synthesis and find the global optimum extent of the fitness function. A multiobjective function according to the damping ratio and damping factor is considered to enhance the damping of the modes, and the objective function is obtained as follows [54]: 


$$
F(X)=F_{1}+\alpha F_{2}=\sum_{\sigma_{i} \geq \sigma_{0}}\left(\sigma_{0}-\sigma_{i}\right)^{2}+\alpha \sum_{\xi_{i} \geq \xi_{0}}\left(\xi_{0}-\xi_{i}\right)^{2},
$$

where $\sigma_{i}$ and $\zeta_{i}$ are the damping factor and the damping ratio of the $i$ th mode, respectively. The weighting parameter $(\alpha)$ is used to combine both objective functions simultaneously. The effect of the objective function is shown in Figure 4. The objective function and constrained optimization problem can be described by the following equation for various loading conditions:

$$
\begin{aligned}
& \text { Minimize } F(X) \\
& \text { subject to } K_{i}^{\min } \leq K_{i} \leq K_{i}^{\max } \\
& T_{j i}^{\min } \leq T_{j i} \leq T_{j i}^{\max } \\
& j=1, \ldots, 4 .
\end{aligned}
$$

The gain $(K)$ and time constants $(T)$ of controllers are defined by ARSO. In most previous works, the washout time constant for both PSS and SVC controllers is $T_{W i}=10 \mathrm{~s}$. The decision variables' typical ranges are [1-100] for $K_{i}$ and [0.01-1.5] for $T_{1 i}$ to $T_{4 i}$.

\section{Rat Swarm Optimization (RSO)}

Rat Swarm Optimization (RSO) is a novel metaheuristic algorithm that is inspired by the following and attacking behaviors of rats [52]. Rats are regional animals that live in swarms of both males and females. Rats' performance is very aggressive in many cases, which may result in the death of some animals. In this approach, the following and aggressive actions of rats are mathematically modelled to perform optimization [52]. Similar to the other population-based optimization techniques, the rat swarm optimizer starts with a set of random solutions which represent the rat's position in the search space. This random set is evaluated repeatedly by an objective function and improved based on the following and aggressive behaviors of rats. In the original version of the RSO technique, the initial positions of eligible solutions (rats' positions) are determined randomly in the search space as follows:

$x_{i}=x_{i \min }+\operatorname{rand} \times\left(x_{i \max }-x_{i \min }\right), \quad i=1,2, \ldots, N$,

where $x_{i \min }$ and $x_{i \max }$ are the lower and upper bounds for the $i$ th variable, respectively, and $N$ is the total number of agents. Generally, rats are following the bait in a group through their social painful behavior. Mathematically, to describe this performance of rats, it is assumed that the greatest search agent has the knowledge of bait placement. Therefore, the other search agents can inform their locations with respect to the greatest search agent obtained until now. The following equation has been suggested to present the attacking process of rats using bait and produce the updated next position of rats [52]:

$$
\vec{P}_{i}(x+1)=\left|\vec{P}_{r}(x)-\vec{P}\right|,
$$

where $\vec{P}_{i}(x+1)$ defines the updated positions of $i$ th rats and $\vec{P}_{r}(x)$ is the best optimal solution found so far. In the

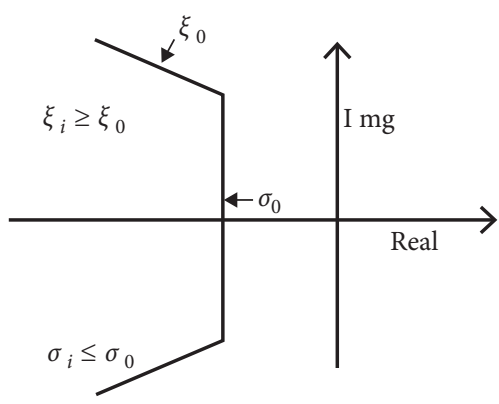

Figure 4: D-shaped area for modes.

abovementioned equation, $\vec{P}$ can be obtained using the following equation:

$$
\vec{P}=A \times \vec{P}_{i}(x)+C \times\left(\vec{P}_{r}(x)-\vec{P}_{i}(x)\right),
$$

where $\vec{P}_{i}(x)$ defines the positions of $i$ th rats, and parameters $A$ and $C$ are calculated as follows:

$$
\begin{aligned}
& A=R-x \times\left(\frac{R}{\text { Iter }_{\text {max }}}\right), \quad x=1,2,3, \ldots, \text { Iter }_{\text {max }}, \\
& C=2 \times \text { rand. }
\end{aligned}
$$

Here, the parameter $R$ is a random number $[1,5]$, and $C$ is a random number between $[0,2][52] . x$ is the current iteration of the optimization process and Iter $_{\max }$ is the maximum number of iterations. Equation (8) updates the locations of search agents and saves the best solution. The pseudocode of the RSO is presented in Algorithm 1.

\section{Adaptive Rat Swarm Optimization (ARSO)}

Even though the performance of RSO to obtain the global optima is better than that of other evolutionary algorithms such as Moth-Flame Optimization (MFO), Grey Wolf Optimizer (GWO), and Gravitational Search Algorithm (GSA) [52], the algorithm may face some trouble in finding better results by exploring complex functions.

To increase the performance and efficiency of RSO, this research introduces an adaptive version of the algorithm using the idea of opposition-based learning (OBL). As mentioned before, RSO, as a member of population-based optimization algorithm, starts with a set of initial solutions and tries to improve performance toward the best solution. In the absence of a priori knowledge about the solution, the random initialization method is used to generate candidate solutions (initial rats' position) based on equation (7). Obviously, the performance and convergence speed are directly related to the distance between the initial solutions and the best solution. In other words, the algorithm has better performance if the randomly generated solutions have a lower value of the objective function. According to this idea and in order to improve the convergence speed and chance of finding the global optima of the standard RSO, this paper proposes an adaptive version of the algorithm (ARSO). In the new ARSO, in the first iteration of the algorithm, after generating the initial random solutions (i.e., 


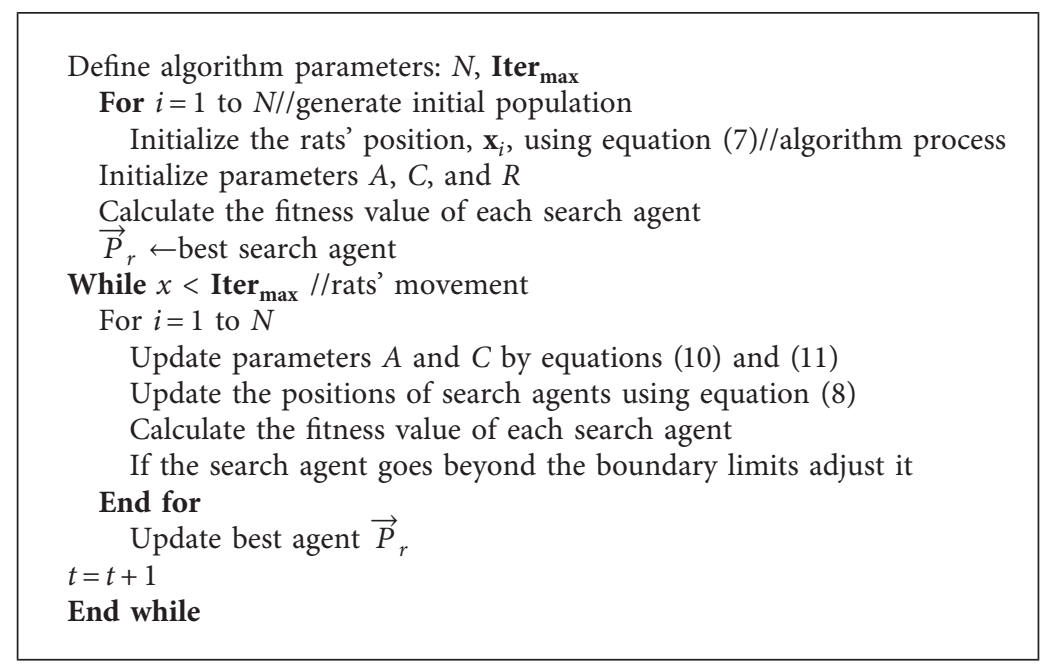

Algorithm 1: Rat swarm optimization.

the rats' positions) using equation (7), the opposite positions of each solution will be generated based on the concept of the opposite number. To describe the new population initialization, it is necessary to define the concept of the opposite number. Let us consider $N$-dimensional vector $X$ as follows:

$$
X=\left(x_{1}, x_{2}, \ldots, x_{N}\right) \text {, }
$$

where $x_{i} \in\left[x_{i \min }, x_{i \max }\right]$. Then, the opposite point of $x_{i}$, which denoted by $\bar{x}_{i}$, is defined by

$$
\bar{x}_{i}=\left(x_{i \max }-x_{i \min }\right)-x_{i}, \quad i=1,2, \ldots, N .
$$

To apply the concept of the opposite number in the population initialization of the ARSO, we consider $x_{i}$ be a randomly generated solution in the $N$-dimensional problem space (i.e., candidate solution). For this random solution, its opposite will be generated using equation (13) and denoted by $\bar{x}_{i}$. Then, both solutions (i.e., $x_{i}$ and $\bar{x}_{i}$ ) will be evaluated by the objective function $f(\cdot)$. Therefore, if $f\left(\bar{x}_{i}\right)$ is better than $f\left(x_{i}\right)$ (i.e., $f\left(\bar{x}_{i}\right)<f\left(x_{i}\right)$ ), the agent $x_{i}$ will be replaced by $\bar{x}_{i}$; otherwise, we continue with $x_{i}$. Hence, in the first iteration, the initial solution and its opposite are evaluated simultaneously to continue with better (fitter) starting agents.

Although the ARSO is capable of outperforming the standard algorithm in terms of efficiency, it still suffers from the problem of becoming trapped in local optima and is not suitable for highly complex problems. In other words, during the search process, occasionally, some agents fall into a local minimum and do not move for several iterations. To overcome these weaknesses and to increase the exploration and search capability, in the proposed ARSO, at each iteration, the worst solution yielding the largest fitness value (in minimization problems) will be replaced by a new solution according to the following equation:

$$
x_{\text {worst }}= \begin{cases}\operatorname{rand}_{1} \times \vec{P}_{r}(x), & \text { if } \operatorname{rand}_{3} \leq 0.5, \\ \left(x_{i \max }-x_{i \min }\right)-x_{i}, & \text { if } \operatorname{rand}_{3}>0.5,\end{cases}
$$

where $x_{\text {worst }}$ is the solution with the maximum value of the objective function and $\operatorname{rand}_{1}$, rand $_{2}$, and $\operatorname{rand}_{3}$ are random numbers between 0 and 1 . The new approach exchanges the position vector of a least ranked rat with its opposite or based on the best solution found so far $\left(\vec{P}_{r}(x)\right)$ in each generation. This process tries to modify the result, by keeping diversity in the population, and explores new regions across the problem search space.

In summary, the two phases of the proposed ARSO algorithm are implemented as follows: first, the initial random solutions and their opposites are generated, and then, these solutions are evaluated according to the objective function to start the algorithm with fitter (better) solutions. Second, the population updating phase is conducted by updating the current solutions, and then, these solutions are evaluated again to replace the worst solution with a new one. The pseudocode of the proposed ARSO is presented in Algorithm 2.

\section{Model Verification}

In this section, the effectiveness verification of the proposed method will be investigated. For this aim, the performance of ARSO is compared with the standard version of the algorithm as well as some well-known metaheuristic algorithms on a collection of benchmark test functions from the literature $[55,56]$. These are all minimization problems that can be used to assess the robustness and search efficiency of new optimization algorithms. Tables 1 and 2 show the mathematical formulation and features of these test functions.

The results and performance of the proposed ARSO are compared with those of the original RSO and other wellestablished optimization algorithms, including Particle Swarm Optimization (PSO) [57], Moth-Flame Optimization (MFO) [58], and Multi-Verse Optimizer (MVO) [59]. For both ARSO and RSO, the size of solutions $(N)$ and maximum iteration number $\left(\right.$ Iter $_{\max }$ ) are considered equal to 50 and 1000 , respectively. Because metaheuristic approaches are stochastic, the findings of a single run may be erroneous, and the algorithms may find better or worse solutions than those 
Define algorithm parameters: $N$, Iter ${ }_{\max }$

For $i=1$ to $N / /$ generate initial population

Initialize the rats' position, $\mathbf{x}_{i}$, using equation (7)

Evaluate opposite of rats' position, $\bar{x}_{i}$, based on equation (13)

If $f\left(\bar{x}_{i}\right)<f\left(x_{i}\right)$

Replace $\mathbf{x}_{i}$ with $\bar{x}_{i}$

End if

End for//algorithm process

Initialize parameters $A, C$, and $R$

Calculate the fitness value of each search agent

$\vec{P}_{r} \leftarrow$ best search agent

While $x<$ Iter $_{\text {max }} / /$ rats' movement

For $i=1$ to $N$

Update parameters $A$ and $C$ by equations (10) and (11)

Update the positions of search agents using equation (8)

Calculate the fitness value of each search agent

If the search agent goes beyond the boundary limits adjust it

End for

Change the worst agent with a new one using equation (14)

$t=t+1$

Update best agent $\vec{P}_{r}$

End while

Algorithm 2: Adaptive rat swarm optimization.

TABle 1: Description of unimodal benchmark functions.

\begin{tabular}{lccc}
\hline Function & Range & $f_{\min }$ & $n(\operatorname{dim})$ \\
\hline$F_{1}(X)=\sum_{i=1}^{n} x_{i}^{2}$ & {$[-100,100]^{n}$} & 0 & 30 \\
$F_{2}(X)=\sum_{i=1}^{n}\left|x_{i}\right|+\prod_{i=1}^{n}\left|x_{i}\right|$ & {$[-10,10]^{n}$} & 0 & 0 \\
$F_{3}(X)=\sum_{i=1}^{n}\left(\sum_{j=1}^{j} x_{j}\right)^{2}$ & {$[-100,100]^{n}$} & 0 & 30 \\
$F_{4}(X)=\max _{i}\left\{\left|x_{i}\right|, 1 \leq i \leq n\right\}$ & {$[-100,100]^{n}$} & 0 & 30 \\
$F_{5}(X)=\sum_{i=1}^{n-1}\left[100\left(x_{i+1}-x_{i}^{2}\right)^{2}+\left(x_{i}-1\right)^{2}\right]$ & {$[-30,30]^{n}$} & 0 \\
$F_{6}(X)=\sum_{i=1}^{n} i x_{i}^{4}+\operatorname{random}[0.1)$ & {$[-1.28,1.28]^{n}$} & 30 \\
\hline
\end{tabular}

TABLE 2: Description of multimodal benchmark functions.

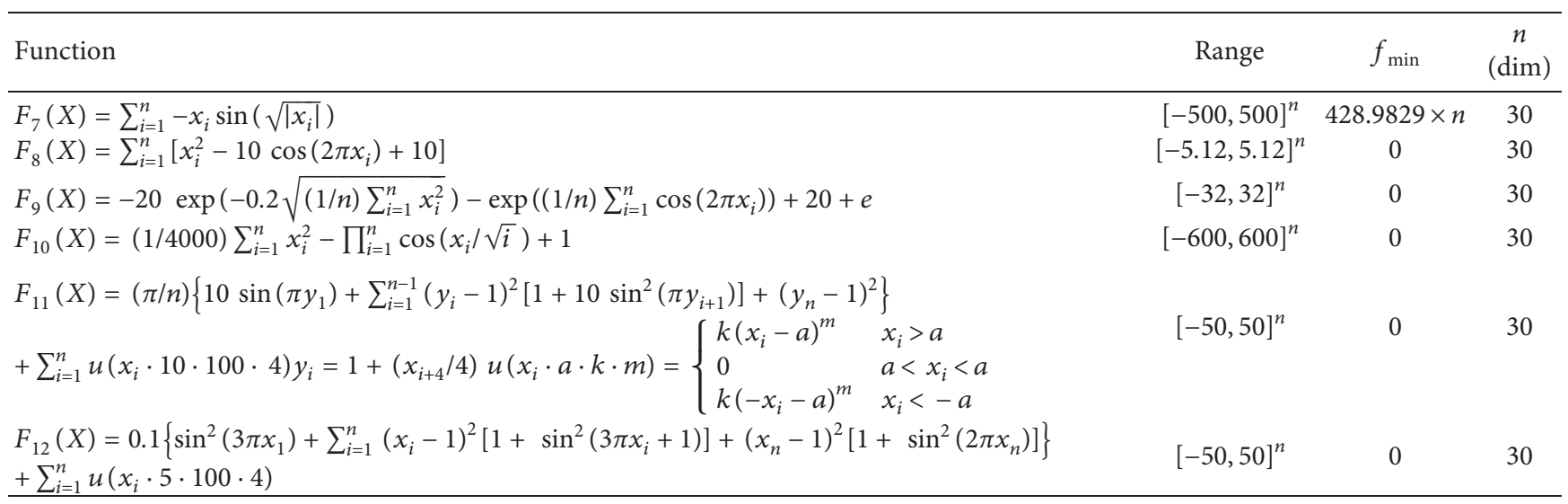

previously found. As a result, statistical analysis should be used to make a fair comparison and evaluate the algorithms' effectiveness. In order to address this issue, 30 separate runs are conducted for the specified algorithms, and the mean and standard deviation of the results are calculated and presented in Tables 3 and 4.
As derived from the results of Tables 3 and 4, the performance of ARSO on both unimodal and multimodal functions outperforms the standard version of the algorithm and other methods significantly. The better mean values show that ARSO performs better than RSO and proves the effectiveness of the modification. In addition, the standard 
TABLE 3: Comparison of different methods in solving unimodal test functions in Table 1.

\begin{tabular}{|c|c|c|c|c|c|c|}
\hline Function & Statistics & ARSO & RSO & PSO & MFO & MVO \\
\hline \multirow{2}{*}{$F_{1}$} & Mean & $0.00 \mathrm{E}+00$ & $6.09 E-32$ & $4.98 E-09$ & $3.15 E-04$ & $2.81 E-01$ \\
\hline & Std & $0.00 \mathrm{E}+00$ & $5.67 E-35$ & $1.40 E-08$ & $5.99 E-04$ & $1.11 E-01$ \\
\hline \multirow{2}{*}{$F_{2}$} & Mean & $0.00 \mathrm{E}+00$ & $0.00 \mathrm{E}+00$ & $7.29 E-04$ & $3.71 E+01$ & $3.96 E-01$ \\
\hline & Std & $0.00 \mathrm{E}+00$ & $0.00 \mathrm{E}+00$ & $1.84 E-03$ & $2.16 E+01$ & $1.41 E-01$ \\
\hline \multirow{2}{*}{$F_{3}$} & Mean & $0.00 \mathrm{E}+00$ & $1.10 E-18$ & $1.40 E+01$ & $4.42 E+03$ & $4.31 E+01$ \\
\hline & Std & $0.00 \mathrm{E}+00$ & $4.47 E-19$ & $7.13 E+00$ & $3.71 E+03$ & $8.97 E+00$ \\
\hline \multirow{2}{*}{$F_{4}$} & Mean & $0.00 \mathrm{E}+00$ & $4.67 E-07$ & $6.00 E-01$ & $6.70 E+01$ & $8.80 E-01$ \\
\hline & Std & $0.00 \mathrm{E}+00$ & $1.96 E-08$ & $1.72 E-01$ & $1.06 E+01$ & $2.50 E-01$ \\
\hline \multirow{2}{*}{$F_{5}$} & Mean & $4.71 \mathrm{E}-03$ & $6.13 E+00$ & $4.93 E+01$ & $3.50 E+03$ & $1.18 E+02$ \\
\hline & Std & $0.00 \mathrm{E}+00$ & $7.97 E-01$ & $3.89 E+01$ & $3.98 E+03$ & $1.43 E+02$ \\
\hline \multirow{2}{*}{$F_{6}$} & Mean & $6.32 \mathrm{E}-07$ & $9.49 E-06$ & $6.92 E-02$ & $3.22 E-01$ & $2.02 E-02$ \\
\hline & Std & $4.75 E-07$ & $1.83 E-05$ & $2.87 E-02$ & $2.93 E-01$ & $7.43 E-03$ \\
\hline
\end{tabular}

TABLE 4: Comparison of different methods in solving multimodal test functions in Table 2.

\begin{tabular}{|c|c|c|c|c|c|c|}
\hline Function & Statistics & ARSO & RSO & PSO & MFO & MVO \\
\hline$F_{7}$ & $\begin{array}{l}\text { Mean } \\
\text { Std }\end{array}$ & $\begin{array}{c}-1.25 \mathrm{E}+04 \\
2.60 \mathrm{E}+00\end{array}$ & $\begin{array}{c}-8.57 E+03 \\
4.23 E+02\end{array}$ & $\begin{array}{c}-6.01 E+03 \\
1.30 E+03\end{array}$ & $\begin{array}{c}-8.04 E+03 \\
8.80 E+02\end{array}$ & $\begin{array}{c}-6.92 E+03 \\
9.19 E+02\end{array}$ \\
\hline$F_{8}$ & $\begin{array}{c}\text { Mean } \\
\text { Std }\end{array}$ & $\begin{array}{l}0.00 \mathrm{E}+00 \\
0.00 \mathrm{E}+00\end{array}$ & $\begin{array}{l}1.57 E+02 \\
7.39 E+01 \\
\end{array}$ & $\begin{array}{l}4.72 E+01 \\
1.03 E+01 \\
\end{array}$ & $\begin{array}{l}1.63 E+02 \\
3.74 E+01 \\
\end{array}$ & $\begin{array}{l}1.01 E+02 \\
1.89 E+01 \\
\end{array}$ \\
\hline$F_{9}$ & $\begin{array}{c}\text { Mean } \\
\text { Std }\end{array}$ & $\begin{array}{l}8.88 E-16 \\
0.00 E+00\end{array}$ & $\begin{array}{r}7.40 \mathrm{E}-17 \\
6.42 E+00 \\
\end{array}$ & $\begin{array}{l}3.86 E-02 \\
2.11 E-01\end{array}$ & $\begin{array}{l}1.60 E+01 \\
6.18 E+00\end{array}$ & $\begin{array}{l}1.15 E+00 \\
7.87 E-01\end{array}$ \\
\hline$F_{10}$ & $\begin{array}{c}\text { Mean } \\
\text { Std }\end{array}$ & $\begin{array}{l}0.00 \mathrm{E}+00 \\
0.00 \mathrm{E}+00\end{array}$ & $\begin{array}{l}0.00 \mathrm{E}+00 \\
0.00 \mathrm{E}+00\end{array}$ & $\begin{array}{l}5.50 E-03 \\
7.39 E-03\end{array}$ & $\begin{array}{l}5.03 E-02 \\
1.74 E-01\end{array}$ & $\begin{array}{l}5.74 E-01 \\
1.12 E-01 \\
\end{array}$ \\
\hline$F_{11}$ & $\begin{array}{c}\text { Mean } \\
\text { Std }\end{array}$ & $\begin{array}{l}2.90 E-03 \\
4.00 E-03\end{array}$ & $\begin{array}{l}5.52 E-01 \\
8.40 E+00 \\
\end{array}$ & $\begin{array}{l}1.05 E-2 \\
2.06 E-2 \\
\end{array}$ & $\begin{array}{l}1.26 E+00 \\
1.83 E+00 \\
\end{array}$ & $\begin{array}{l}1.27 E+00 \\
1.02 E+00\end{array}$ \\
\hline$F_{12}$ & $\begin{array}{c}\text { Mean } \\
\text { Std }\end{array}$ & $\begin{array}{l}2.15 E-02 \\
3.72 E-02\end{array}$ & $\begin{array}{l}6.05 E-02 \\
7.43 E-01\end{array}$ & $\begin{array}{l}4.03 E-01 \\
5.39 E-01\end{array}$ & $\begin{array}{l}7.24 E-01 \\
1.48 E+00\end{array}$ & $\begin{array}{l}6.60 E-02 \\
4.33 E-02\end{array}$ \\
\hline
\end{tabular}

deviations of the results by ARSO in 30 independent runs for most functions are smaller than those calculated using RSO and other techniques, which shows the additional stability of the suggested method.

In addition, the convergence progress curves of ARSO for benchmark test functions are compared to those of RSO, PSO, MFO, and MVO in Figure 5. The curves are plotted against the iteration count, which is in the hundreds. According to the graphs, the ARSO outperforms other algorithms in all cases. Because of its effective modifications, the curves of test functions show that ARSO is capable of thoroughly exploring the search space and identifying the most promising region in fewer iterations.

\section{Practical Applications}

A four-machine, two-area study system, shown in Figure 6, is considered for the damping control design. Each area consists of two generator units. All generators are equipped with simple exciters and have the same parameters. The rating of each generator is $900 \mathrm{MVA}$ and $20 \mathrm{kV}$. Each of the units is connected through transformers to the $230 \mathrm{kV}$ transmission line. There is a power transfer of $400 \mathrm{MW}$ from area 1 to area 2 . Each synchronous generator of the multimachine power system is simulated using a third-order model. The detailed bus data, line data, and the dynamic characteristics for the machines, exciters, and loads are given in [23]. The loads are modelled as constant impedances. On the basis of participation factors [24], two PSSs are installed in generators 1 and 3. The dynamics of the machines are given in Appendix A. The desirable parameters of PSS and SVC controllers will be obtained using the ARSO modelled [53]. The proposed controllers' performance is evaluated using two different loading conditions. Table 5 shows two operating conditions for evaluating the performance of the proposed controllers.

Table 6 presents the achieved controller parameters by ARSO and RSO. In addition, the system close-loop eigenvalue and minimum damping coefficient are reported in Table 7 for both methods. By computing the eigenvalues of the linearized system model, it is found that the system has four interarea modes. It demonstrates that applying the ARSO method is an effective approach to increase the global searching capability and improve performance stability.

A three-phase fault of $100 \mathrm{~ms}$ duration in the middle of one of the transmission lines linking buses 7 and 8 is used to demonstrate the effectiveness and resilience of the proposed controller's performance under transient conditions. The responses of the suggested controllers are compared to the responses of the PSS and SVC damping controller individual designs to evaluate the performance of the proposed simultaneous design technique. Figures 7 and 8 depict interarea 
F1
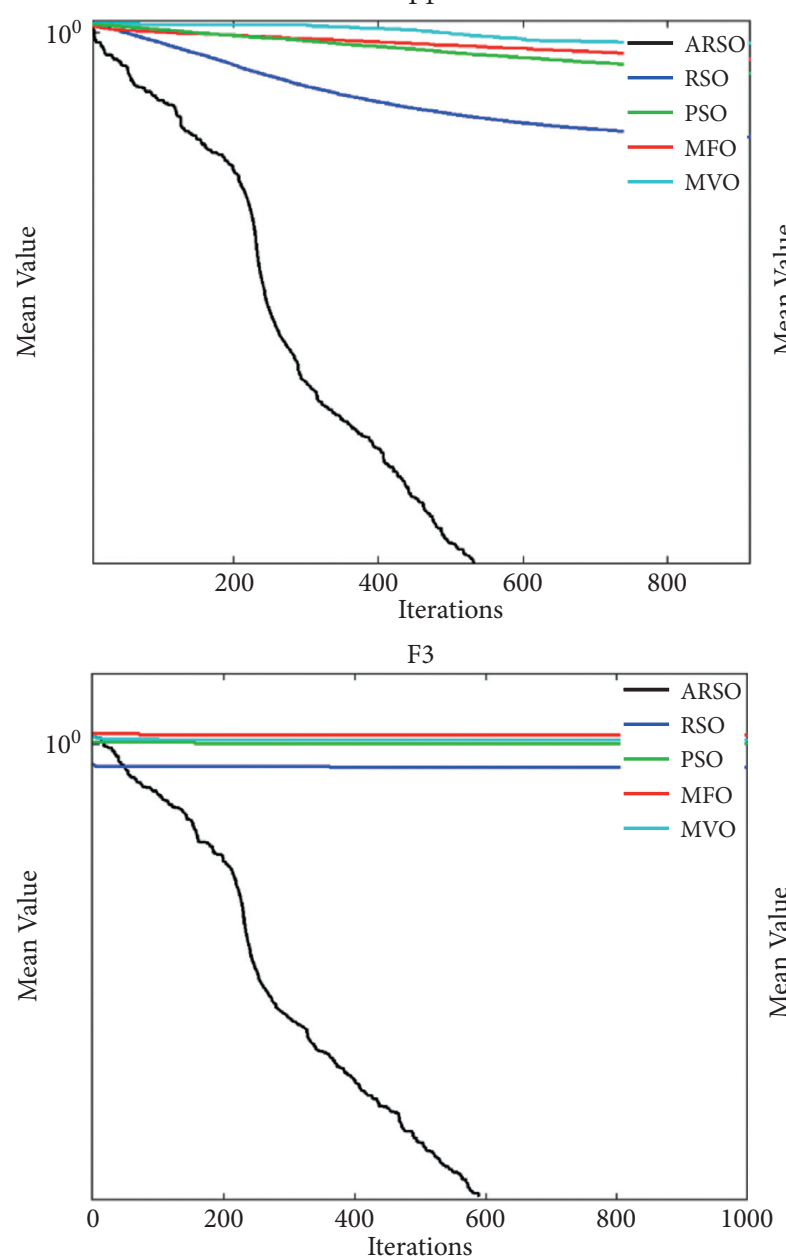

F5

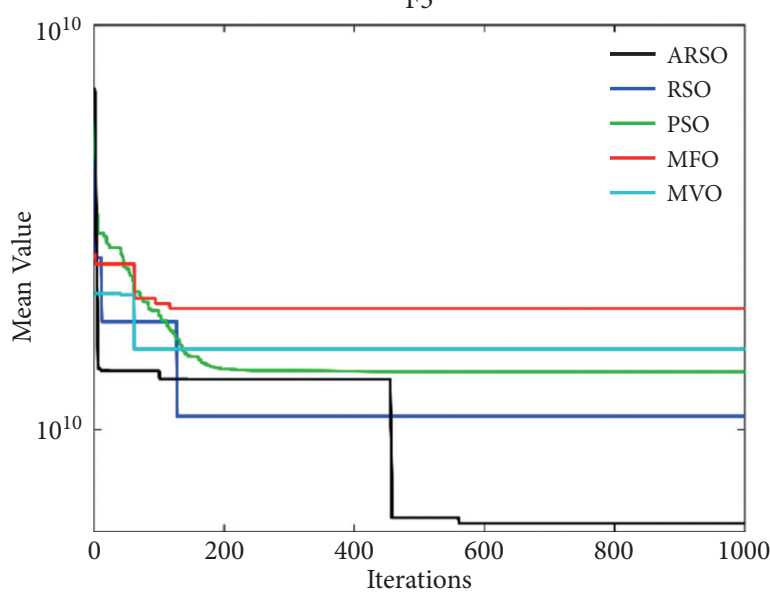

F2

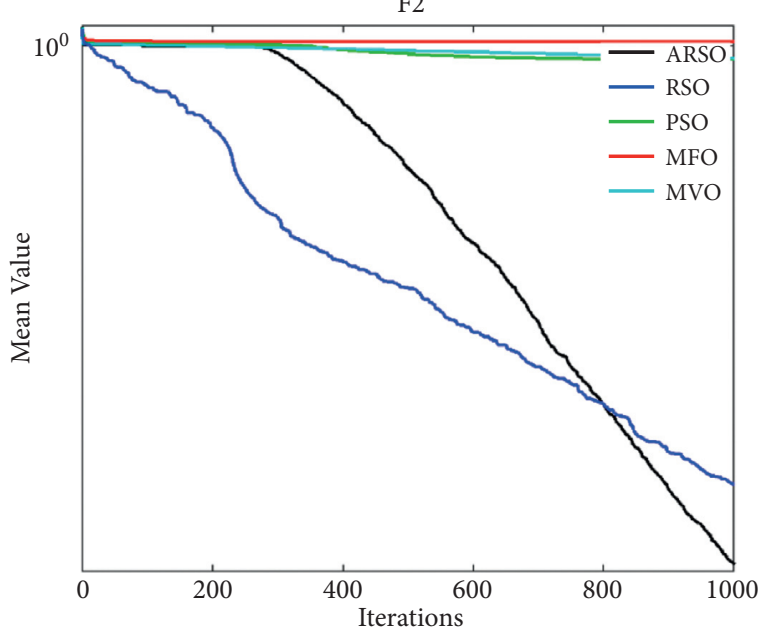

F4

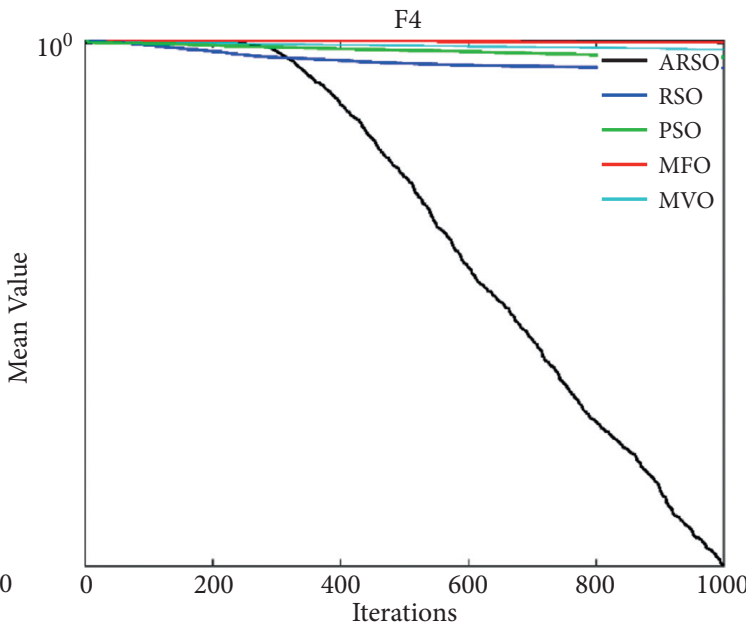

F6

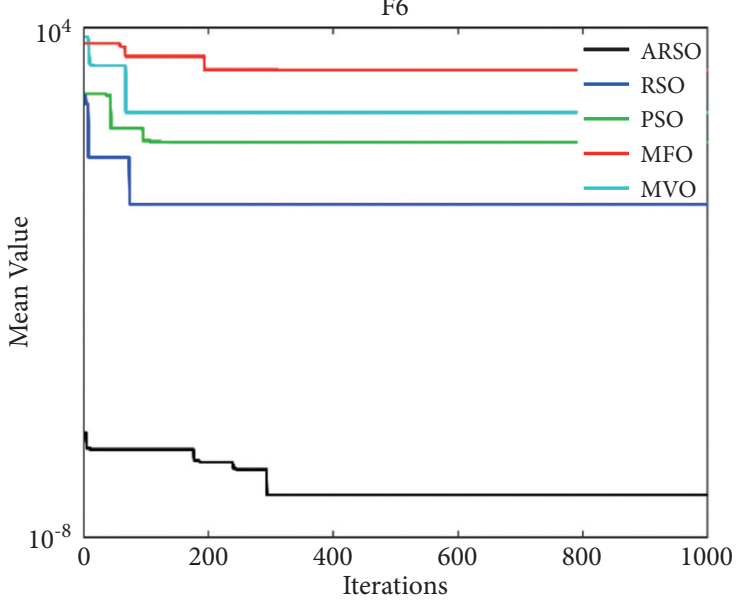

(a)

FIGURE 5: Continued. 

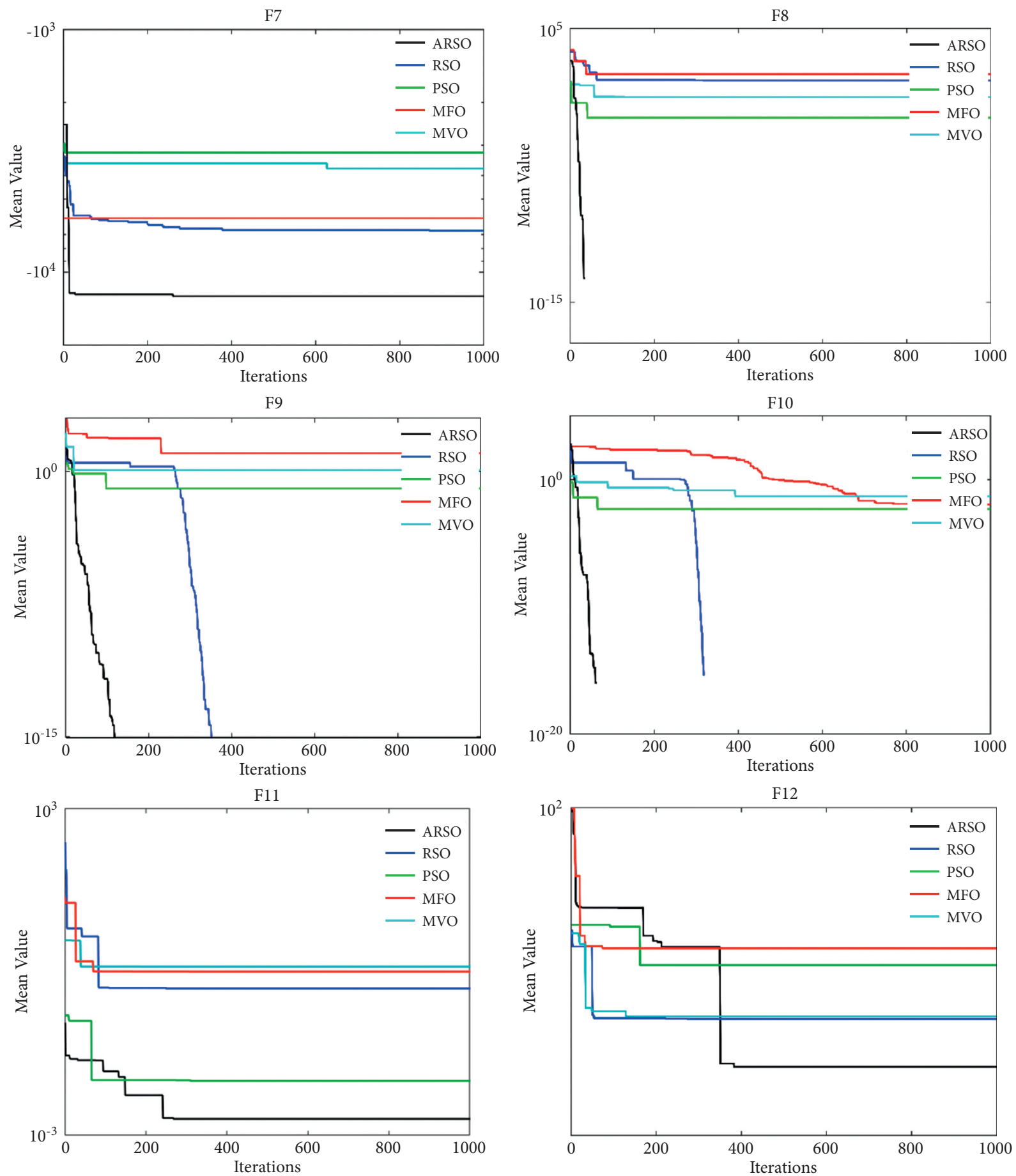

(b)

Figure 5: Comparison of convergence curves of ARSO and selected algorithms for $F_{1}-F_{12}$.

and local oscillation modes with coordinated and uncoordinated controller designs, respectively. The suggested approach's simultaneous design of the PSS and SVC damping controller considerably enhances the stability performance of the example power system, and low-frequency oscillations are well damped out, as seen in these figures. 


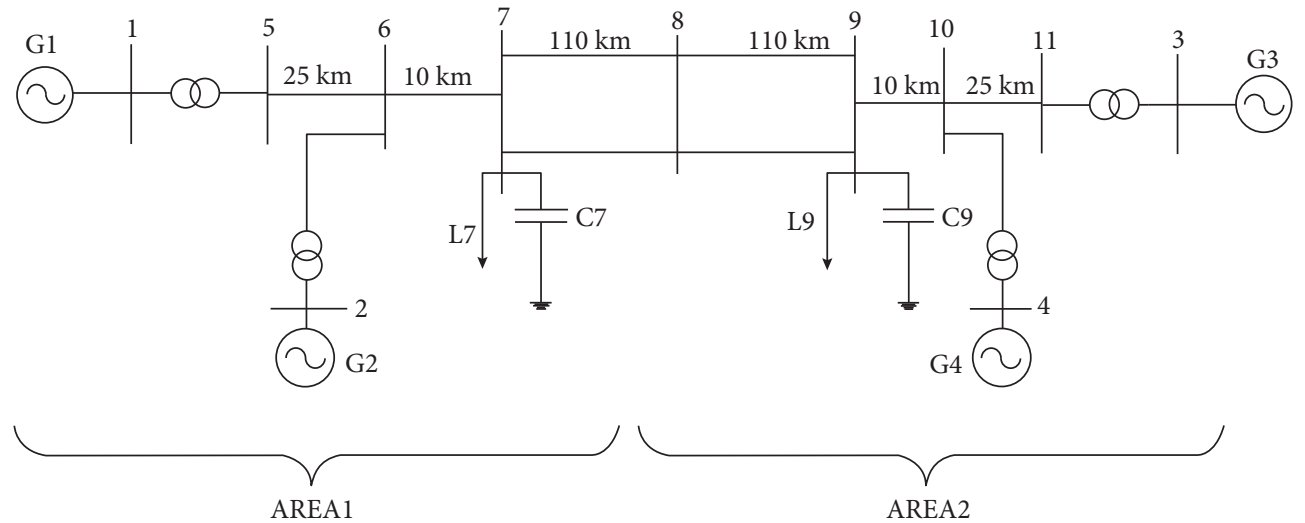

Figure 6: Single-linear block diagram of the system under study.

TABLE 5: System operating conditions.

\begin{tabular}{lcccc}
\hline Generator & Case 1 & & Case 2 \\
\hline G1 & P (p.u) & Q (p.u) & P (p.u) & 0.5556 \\
G2 & 0.7778 & 0.2056 & 0.5556 & 0.2056 \\
G3 & 0.5556 & 0.2611 & 1.3739 & 0.2611 \\
G4 & 0.8020 & 0.0697 & 0.5556 & 0.1502 \\
\hline
\end{tabular}

TABLe 6: Results obtained by ARSO and RSO.

\begin{tabular}{rrccccc}
\hline Algorithm & & $K$ & $T_{1}$ & $T_{2}$ & $T_{3}$ \\
\hline \multirow{3}{*}{ Coordinated with RSO } & PSS1 & 30.45 & 0.267 & 0.973 & 0.021 & 0.176 \\
& PSS2 & 28.46 & 0.1893 & 0.752 & 0.854 & 1.249 \\
& SVC & 24.94 & 0.1232 & 0.0745 & 0.523 \\
\hline \multirow{3}{*}{ Coordinated with ARSO } & PSS1 & 24.06 & 0.854 & 0.432 & 0.283 & 1.374 \\
& PSS2 & 15.03 & 0.56 & 0.0287 & 0.0547 & 0.866 \\
& SVC & 47.93 & 0.034 & 0.23 & 0.0582 \\
\hline
\end{tabular}

TABLE 7: Eigenvalues for designed PSSs by ARSO and RSO.

\begin{tabular}{lcc}
\hline & LFO & Frequency \\
\hline Without PSSs & $0.04439 \pm 4.0310$ & 0.641 \\
Coordinated with RSO & $-0.948 \pm 4.385$ & 0.697 \\
Coordinated with ARSO & $-1.597 \pm 6.021$ & 0.992 \\
\hline
\end{tabular}
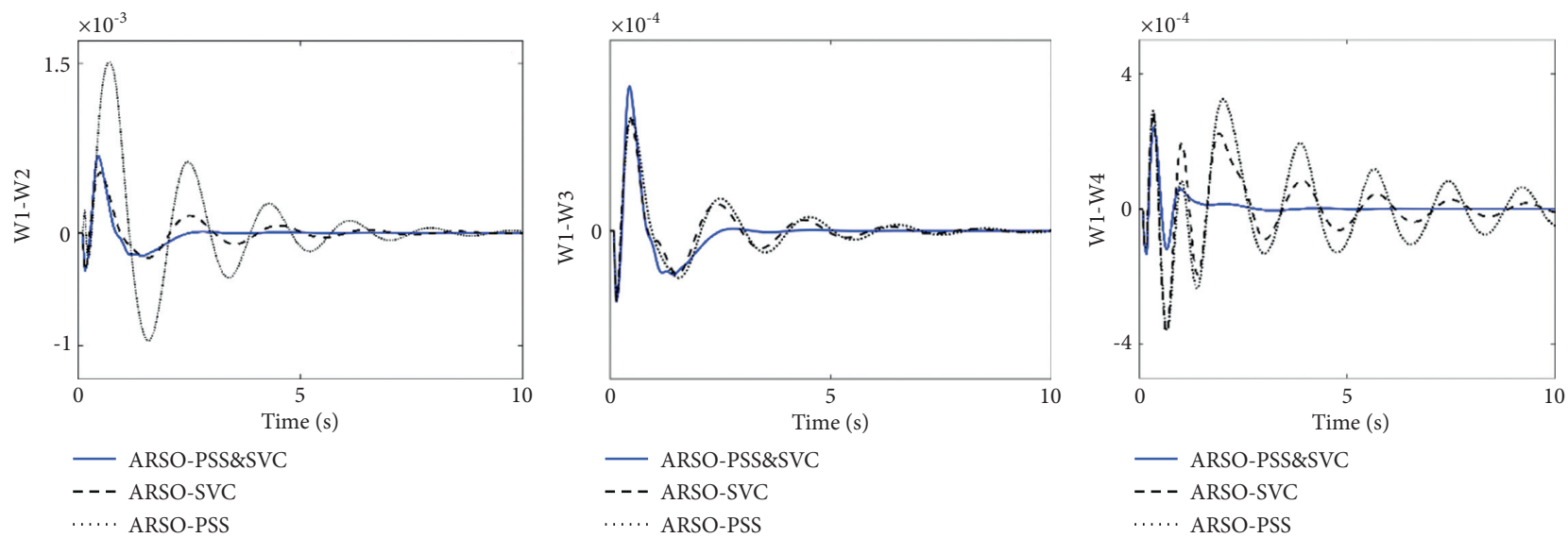

FIGURE 7: Interarea and local mode of oscillations for case 1. 

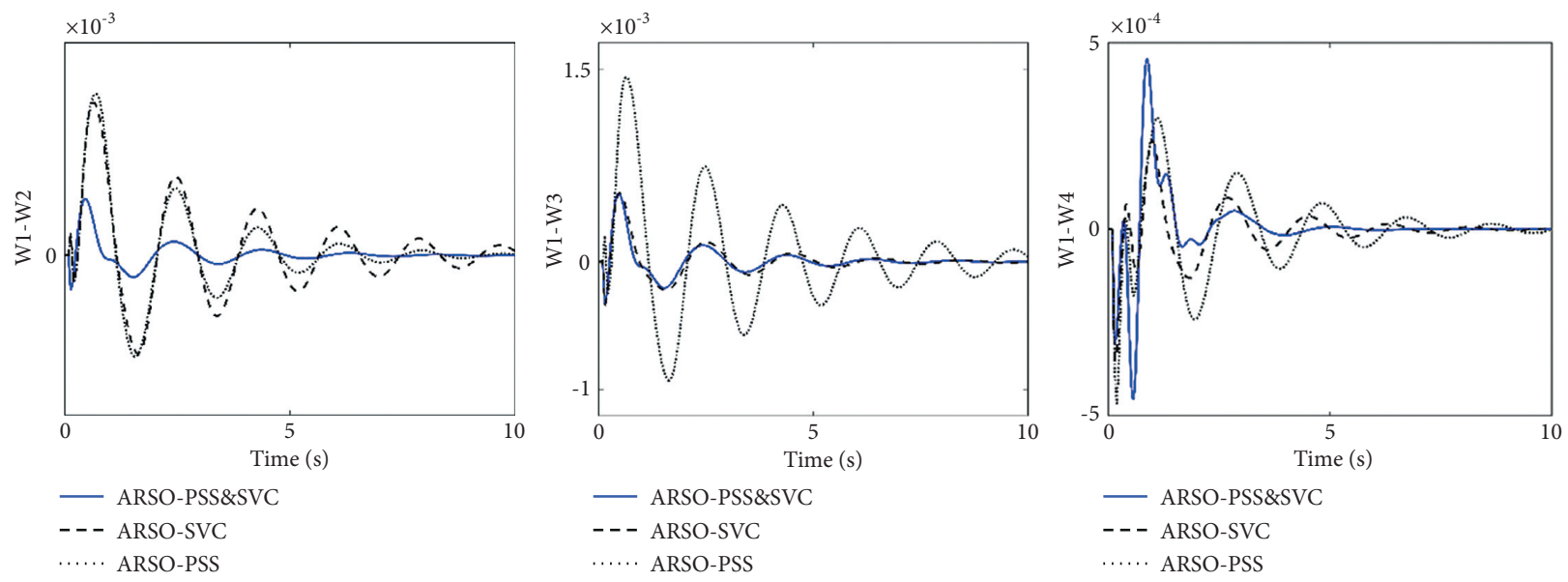

Figure 8: Interarea and local mode of oscillations for case 2.

\section{Conclusions}

An adaptive optimization algorithm based on a rat swarm optimizer (RSO), namely, adaptive rat swarm optimization (ARSO), has been introduced for coordinated tuning of PSSand SVC-based controllers in power systems. In the proposed method, instead of a random initial population, the algorithm starts the search process with fitter solutions using the concept of the opposite number. In addition, in each iteration of the optimization, the new algorithm replaces the worst solution with its opposite or a random part of the best solution to avoid getting trapped in local optima and increase the global search ability of the algorithm. As per the results and findings, ARSO has demonstrated strongly competitive results for most of the benchmark functions and outperforms the standard RSO and also other algorithms in a statistically significant manner. The new ARSO algorithm has been successfully applied for tuning of PSS- and SVCbased controllers. According to the numerical experiment, the ARSO algorithm outperforms the other methods and could provide better damping of power system oscillation.

\section{Appendix}

\section{A Dynamic Model}

The dynamics of each synchronous machine is given by [60]

$$
\begin{aligned}
\dot{\delta}_{i} & =\omega_{b}\left(\omega_{i}-1\right), \\
\dot{\omega}_{i} & =\frac{1}{M_{i}}\left(P_{m i}-P_{e i}-D_{i}\left(\omega_{i}-1\right)\right), \\
E_{q i}^{\prime} & =\frac{1}{T_{d o i}^{\prime}}\left(E_{f d i}-\left(\dot{x}_{d i}-x_{d i}^{\prime}\right) i_{d i}-E_{q i}^{\prime}\right), \\
E_{f i}^{\prime}= & \frac{1}{\prime}\left(K_{A i}\left(v_{r e f i}-v_{i}+u_{i}\right)-E_{f d i}\right), \\
T_{e i}= & E_{q i}^{\prime} i_{q i}\left(x_{q i}-x_{d i}^{\prime}\right) i_{d i} i_{q i} .
\end{aligned}
$$

\section{Data Availability}

The data that support the findings of this study are available from the corresponding author upon reasonable request.

\section{Conflicts of Interest}

The authors declare no conflicts of interest.

\section{References}

[1] P. Kundur, N. J. Balu, and M. G. Lauby, Power System Stability and Control, McGraw-Hill, New York, NY, USA, 1994.

[2] P. Dey, A. Saha, P. Srimannarayana, A. Bhattacharya, and B. Marungsri, "A realistic approach towards solution of load frequency control problem in interconnected power systems," Journal of Electrical Engineering \& Technology, pp. 1-30, 2021, in Press.

[3] P. Dey, A. Saha, A. Bhattacharya, and B. Marungsri, "Analysis of the effects of PSS and renewable integration to an inter-area power network to improve small signal stability," Journal of Electrical Engineering \& Technology, vol. 15, no. 5, pp. 2057-2077, 2020.

[4] Y. Chompoobutrgool, L. Vanfretti, and M. Ghandhari, "Survey on power system stabilizers control and their prospective applications for power system damping using synchrophasor-based wide-area systems," European Transactions on Electrical Power, vol. 21, no. 8, pp. 2098-2111, 2011.

[5] N. G. Hingorani, “"Flexible AC transmission”," IEEE Spectrum, vol. 30, no. 4, pp. 40-45, 1993.

[6] P. Dey, S. Mitra, A. Bhattacharya, and P. Das, "Comparative study of the effects of SVC and TCSC on the small signal stability of a power system with renewables," Journal of Renewable and Sustainable Energy, vol. 11, no. 3, Article ID 033305, 2019.

[7] M. Eslami, H. Shareef, A. Mohamed, and M. Khajehzadeh, "A survey on flexible AC transmission systems (FACTS)," Przeglad Elektrotechniczny, vol. 88, no. 1a, pp. 1-11, 2012.

[8] J.-H. Chen, W.-J. Lee, and M.-S. Chen, "Using a static var compensator to balance a distribution system," in Proceedings of the IAS '96. Conference Record of the 1996 IEEE Industry Applications Conference Thirty-First IAS Annual Meeting, pp. 2321-2326, San Diego, CA, USA, October 1996.

[9] P. M. Anderson and A. A. Fouad, Power System Control and Stability, John Wiley \& Sons, Hoboken, NJ, USA, 2008. 
[10] M. Noroozian and G. Adersson, "Damping of power system oscillations by use of controllable components," IEEE Transactions on Power Delivery, vol. 9, no. 4, pp. 2046-2054, 1994.

[11] M. Eslami, H. Shareef, and M. Khajehzadeh, "Optimal design of damping controllers using a new hybrid artificial bee colony algorithm," International Journal of Electrical Power \& Energy Systems, vol. 52, pp. 42-54, 2013.

[12] M. Eslami, H. Shareef, and A. Mohamed, "Application of artificial intelligent techniques in PSS design: a survey of the state-of-the-art methods," Przeglad Elektrotechniczny, vol. 87, no. 4, pp. 188-197, 2011.

[13] M. Eslami, H. Shareef, and A. Mohamed, "Application of PSS and FACTS devices for intensification of power system stability," International Review of Economics Education, vol. 5, no. 2, pp. 552-570, 2010.

[14] M. Khajehzadeh, M. R. Taha, A. El-Shafie, and M. Eslami, "Search for critical failure surface in slope stability analysis by gravitational search algorithm," International Journal of the Physical Sciences, vol. 6, no. 21, pp. 5012-5021, 2011.

[15] A. Farah, T. Guesmi, H. Hadj Abdallah, and A. Ouali, "A novel chaotic teaching-learning-based optimization algorithm for multi-machine power system stabilizers design problem," International Journal of Electrical Power \& Energy Systems, vol. 77, pp. 197-209, 2016.

[16] S. M. Abd-Elazim and E. S. Ali, "Coordinated design of PSSs and SVC via bacteria foraging optimization algorithm in a multimachine power system," International Journal of Electrical Power \& Energy Systems, vol. 41, no. 1, pp. 44-53, 2012.

[17] S. Choudhury and T. Dash, "Modified brain storming optimization technique for transient stability improvement of SVC controller for a two machine system," World Journal of Engineering, vol. 18, 2021.

[18] T. Guesmi, B. M. Alshammari, Y. Almalaq, A. Alateeq, and K. Alqunun, "New coordinated tuning of SVC and PSSs in multimachine power system using coyote optimization algorithm," Sustainability, vol. 13, no. 6, Article ID 3131, 2021.

[19] M. A. Kamarposhti, I. Colak, C. Iwendi, S. S. Band, and E. Ibeke, "Optimal coordination of PSS and SSSC controllers in power system using ant colony optimization algorithm," Journal of Circuits, Systems and Computers, Article ID 2250060, 2021, in Press.

[20] B. Baadji, H. Bentarzi, and A. Bakdi, "Comprehensive learning bat algorithm for optimal coordinated tuning of power system stabilizers and static VAR compensator in power systems," Engineering Optimization, vol. 52, no. 10, pp. 1761-1779, 2020.

[21] M. A. Abido and Y. L. Abdel-Magid, "Coordinated design of a PSS and an SVC-based controller to enhance power system stability," International Journal of Electrical Power \& Energy Systems, vol. 25, no. 9, pp. 695-704, 2003.

[22] N. A. M. Kamari, I. Musirin, and A. A. Ibrahim, "Swarm intelligence approach for angle stability improvement of PSS and SVC-based SMIB," Journal of Electrical Engineering \& Technology, vol. 15, no. 3, pp. 1001-1014, 2020.

[23] A. Y. Abdelaziz and E. S. Ali, "Static VAR compensator damping controller design based on flower pollination algorithm for a multi-machine power system," Electric Power Components and Systems, vol. 43, no. 11, pp. 1268-1277, 2015.

[24] M. Eslami, H. Shareef, A. Mohamed, and M. Khajehzadeh, "PSS and TCSC damping controller coordinated design using GSA," Energy Procedia, vol. 14, pp. 763-769, 2012.

[25] M. Eslami, H. Shareef, A. Mohamed, and M. Khajehzadeh, "Gravitational search algorithm for coordinated design of PSS and TCSC as damping controller," Journal of Central South University, vol. 19, no. 4, pp. 923-932, 2012.

[26] M. K. Kar, S. Kumar, A. K. Singh, and S. Panigrahi, "A modified sine cosine algorithm with ensemble search agent updating schemes for small signal stability analysis," International Transactions on Electrical Energy Systems, vol. 31, Article ID e13058, 2021.

[27] J. Bhukya, T. A. Naidu, S. Vuddanti, and C. Konstantinou, "Coordinated control and parameters optimization for PSS, POD and SVC to enhance the transient stability with the integration of DFIG based wind power systems," International Journal of Emerging Electric Power Systems, 2021, in Press.

[28] R. K. Pandey and D. K. Gupta, "Performance evaluation of power oscillation damping controller-firefly algorithm based parameter tuning," Electric Power Components and Systems, vol. 45, no. 19, pp. 2164-2174, 2017.

[29] S. Panda, "Robust coordinated design of multiple and multitype damping controller using differential evolution algorithm," International Journal of Electrical Power \& Energy Systems, vol. 33, no. 4, pp. 1018-1030, 2011.

[30] K. Karthikeyan and P. Lakshmi, "Optimal design of PID controller for improving rotor angle stability using BBO," Procedia Engineering, vol. 38, pp. 889-902, 2012.

[31] S. M. Abd Elazim and E. S. Ali, "Optimal power system stabilizers design via cuckoo search algorithm," International Journal of Electrical Power \& Energy Systems, vol. 75, pp. 99-107, 2016.

[32] G. Naresh, M. Ramalinga Raju, and S. V. L. Narasimham, "Coordinated design of power system stabilizers and TCSC employing improved harmony search algorithm," Swarm and Evolutionary Computation, vol. 27, pp. 169-179, 2016.

[33] E. Afzalan and M. Joorabian, "Analysis of the simultaneous coordinated design of STATCOM-based damping stabilizers and PSS in a multi-machine power system using the seeker optimization algorithm," International Journal of Electrical Power \& Energy Systems, vol. 53, pp. 1003-1017, 2013.

[34] E. Bijami and J. A. Marnani, "Imperialist competitive algorithm for optimal simultaneous coordinated tuning of damping controller," International Journal on Technical and Physical Problems of Engineering (IJTPE), vol. 11, pp. 34-41, 2012.

[35] R. Devarapalli and B. Bhattacharyya, "Application of modified harris hawks optimization in power system oscillations damping controller design," in Proceedings of the International Conference on Power Systems, pp. 1-6, Jaipur, India, December 2019.

[36] M. Eslami, B. Babaei, H. Shareef, M. Khajehzadeh, and B. Arandian, "Optimum design of damping controllers using modified Sperm swarm optimization," IEEE Access, vol. 9, 2021.

[37] M. A. Abido and Y. L. Abdel-Magid, "A tabu search based approach to power system stability enhancement via excitation and static phase shifter control," Electric Power Systems Research, vol. 52, no. 2, pp. 133-143, 1999.

[38] M. A. Abido, "Simulated annealing based approach to PSS and FACTS based stabilizer tuning," International Journal of Electrical Power \& Energy Systems, vol. 22, no. 4, pp. 247-258, 2000.

[39] P. Dhal, "Multi-verse optimizer for dynamic stability analysis using STATCOM and power system stabilizer," Advanced Computing and Intelligent Engineering: Proceedings of ICACIE, vol. 2, Article ID 117, 2020.

[40] R. Devarapalli, B. Bhattacharyya, V. Kumar, and S. Kumar, "Improved moth flame optimization in systematization of 
STATCOM and PSS," Advances in Smart Grid Automation and Industry 4.0, Springer, Berlin, Germany, 2021.

[41] P. Dey, A. Bhattacharya, and P. Das, "Tuning of power system stabilizer for small signal stability improvement of interconnected power system," Applied Computing and Informatics, vol. 16, 2017.

[42] K. Asghari, M. Masdari, F. S. Gharehchopogh, and R. Saneifard, "Multi-swarm and chaotic whale-particle swarm optimization algorithm with a selection method based on roulette wheel," Expert Systems, vol. 38, Article ID e12779, 2021.

[43] D. Butti, S. K. Mangipudi, and S. R. Rayapudi, “An improved whale optimization algorithm for the design of multi-machine power system stabilizer," International Transactions on Electrical Energy Systems, vol. 30, no. 5, Article ID e12314, 2020.

[44] K. Karthikeyan and P. K. Dhal, "A Hybrid BBO-DE optimization with eigen value analysis based transient stability improvement by coordinated design of SVC," Materials Today: Proceedings, vol. 5, no. 1, pp. 1239-1249, 2018.

[45] A. Farah, A. Belazi, K. Alqunun et al., "A new design method for optimal parameters setting of PSSs and SVC damping controllers to alleviate power system stability problem," Energies, vol. 14, no. 21, Article ID 7312, 2021.

[46] A. Rezazadeh, M. Sedighizadeh, and A. Hasaninia, "Coordination of PSS and TCSC controller using modified particle swarm optimization algorithm to improve power system dynamic performance," Journal of Zhejiang University SCIENCE C, vol. 11, no. 8, pp. 645-653, 2010.

[47] M. Tripathy and S. Mishra, "Coordinated tuning of PSS and TCSC to improve hopf bifurcation margin in multimachine power system by a modified bacteria foraging algorithm," International Journal of Electrical Power \& Energy Systems, vol. 66, pp. 97-109, 2015.

[48] A. Hussain, F. Malek, M. Rashid, L. Mohamed, and N. Mohd Affendi, "Optimal coordinated design of multiple damping controllers based on PSS and UPFC device to improve dynamic stability in the power system," Mathematical Problems in Engineering, vol. 2013, Article ID 965282, 15 pages, 2013.

[49] P. R. Sahu, P. K. Hota, and S. Panda, "Modified whale optimization algorithm for coordinated design of fuzzy lead-lag structure-based SSSC controller and power system stabilizer," International Transactions on Electrical Energy Systems, vol. 29, no. 4, Article ID e2797, 2019.

[50] M. Eslami, H. Shareef, A. Mohamed, and M. Khajehzadeh, "Optimal location of PSS using improved PSO with chaotic sequence," in Proceedings of the International Conference on Electrical, Control and Computer Engineering, pp. 253-258, Kuantan, Malaysia, June 2011.

[51] M. Khajehzadeh, M. R. Taha, and M. Eslami, "A new hybrid firefly algorithm for foundation optimization," National Academy Science Letters, vol. 36, no. 3, pp. 279-288, 2013.

[52] G. Dhiman, M. Garg, A. Nagar, V. Kumar, and M. Dehghani, "A novel algorithm for global optimization: rat swarm optimizer," Journal of Ambient Intelligence and Humanized Computing, vol. 12, no. 10, pp. 1-26, 2020.

[53] P. Kundur, M. Klein, G. J. Rogers, and M. S. Zywno, “Application of power system stabilizers for enhancement of overall system stability," IEEE Transactions on Power Systems, vol. 4, no. 2, pp. 614-626, 1989.

[54] M. Khaleghi, M. M. Farsangi, H. Nezamabadi-Pour, and K. Y. Lee, "Pareto-optimal design of damping controllers using modified artificial immune algorithm," IEEE
Transactions on Systems, Man, and Cybernetics, Part C (Applications and Reviews), vol. 41, no. 2, pp. 240-250, 2010.

[55] K. Zervoudakis and S. Tsafarakis, "A mayfly optimization algorithm," Computers \& Industrial Engineering, vol. 145, Article ID 106559, 2020.

[56] E. Rashedi, H. Nezamabadi-Pour, and S. Saryazdi, "GSA: a gravitational search algorithm," Information Sciences, vol. 179, no. 13, pp. 2232-2248, 2009.

[57] J. Kennedy and R. Eberhart, "Particle swarm optimization," in Proceedings of the IEEE International Conference on Neural Networks, pp. 1942-1948, Perth, Australia, November 1995.

[58] S. Mirjalili, "Moth-flame optimization algorithm: a novel nature-inspired heuristic paradigm," Knowledge-Based Systems, vol. 89, pp. 228-249, 2015.

[59] S. Mirjalili, S. M. Mirjalili, and A. Hatamlou, "Multi-verse optimizer: a nature-inspired algorithm for global optimization," Neural Computing and Applications, vol. 27, no. 2, pp. 495-513, 2016.

[60] R. Sadikovic, G. Andersson, and P. Korba, "Damping controller design for power system oscillations," Intelligent $\mathrm{Au}$ tomation \& Soft Computing, vol. 12, no. 1, pp. 51-62, 2006. 